\title{
Kernos
}

Revue internationale et pluridisciplinaire de religion grecque antique

18 | 2005

Varia

\section{Agnès PIGLER, Plotin. Traité 54 (I, 7), Introduction, traduction, commentaires et notes}

\section{André Motte}

\section{OpenEdition}

\section{Journals}

Édition électronique

URL : http://journals.openedition.org/kernos/1746

DOI : 10.4000/kernos. 1746

ISSN : 2034-7871

\section{Éditeur}

Centre international d'étude de la religion grecque antique

Édition imprimée

Date de publication : 1 janvier 2005

Pagination : 562

ISSN : 0776-3824

Référence électronique

André Motte, "Agnès piglen, Plotin. Traité $54(\mathrm{I}, 7)$, Introduction, traduction, commentaires et notes », Kernos [En ligne], 18| 2005, mis en ligne le 09 juillet 2011, consulté le 21 septembre 2020. URL : http:// journals.openedition.org/kernos/1746; DOI : https://doi.org/10.4000/kernos.1746 
Dans de telles conditions, il serait en tout cas nécessaire de pourvoir à nouveau le terme « orphique » de guillemets, de l'intitulé de l'ouvrage jusqu'à la dernière ligne du commentaire ( $c f$. p. 128); et il serait certainement indispensable de recourir en parallèle à l'ouvrage de A. Bernabé \& A.I. Jiménez San Cristóbal, Instrucciones para el más allá. Las laminillas órficas de oro, Madrid, 2001 (qui présente un commentaire circonstancié des aspects les plus importants offerts par toutes les lamelles d'or lamelles de Pella incluses $=$ fr. 496 F Bernabé, - présentées en traduction et accompagnées de l'édition des textes correspondants avec un apparat exhaustif et une bibliographie complète, ainsi que d'un dossier iconographique). N'eût-il d'ailleurs pas été plus opportun d'offrir en traduction au public francophone ce dernier ouvrage?

Claude Calame

(EHESS, Paris)

Agnès Pigler, Plotin. Traité 54 (I, 7), Introduction, traduction, commentaires et notes, Paris, Éd. du Cerf, 2004, 1 vol. 12,5 ×19,5 cm, 194 p. (coll. Les écrits de Plotin). ISBN : 2-204-07415-2.

Cette prestigieuse collection, entreprise à l'initiative et sous la direction de Pierre Hadot, à qui l'on doit la publication des trois premiers volumes ( $c f$. Kernos 1 [1988], p. 253; 5 [1992], p. 349; 8 [1995], p. 307-308) progresse à pas lents mais assurés. Le présent traité, qui est le huitième paru, est le dernier qu'ait écrit Plotin. Très bref - sa traduction compte à peine huit pages -, mais d'une grande densité, il traite «Du premier Bien et des autres biens » et peut être vu comme une petite somme de l'enseignement du philosphe, une sorte de testament spirituel. Plotin y fait sienne la doctrine platonicienne d'un Bien transcendant, ce qui ne l'empêche pas d'adhérer aussi à la conception aristotéliciene d'un Premier moteur immobile. Pour se rapprocher de ce Bien absolu, l'âme est invitée à conformer sa vie à celle de l'intelligence, mais c'est lorsqu'elle est séparée du corps par la mort qu'elle parvient à s'unir plus pleinement au Bien. Cette méditation éthique et métaphysique comporte assurément une dimension religieuse, mais les références à la religion traditionnelle y sont rares. On y parle une fois de l'Hadès comme lieu de la sanction d'une vie mauvaise et, une fois aussi, il y est aussi question des dieux - en l'occurrence les astres - qui « possèdent le Bien sans aucun mal».

A.P., qui enseigne la philosophie à l'Université de Dijon, donne de ce texte une traduction rigoureuse. Son introduction et ses commentaires, fort abondants mais dépouillés de toute vaine érudition, témoignent d'une bonne connaissance de l'œuvre de Plotin et s'avèrent très éclairants pour le lecteur. Comme de coutume, une bibliographie et plusieurs index complètent le travail. Cette publication répond donc bien aux objectifs initiaux qu'avait définis le directeur de la collection et suit fidèlement les modèles qu'il a lui-même donnés.

André Motte (Université de Liège)

Louis Gernet, Polyvalence des images. Testi e frammenti sulla leggenda greca, editi da Antonella Soldani, contributi di Michela Benedetti, Vanessa Ghionzoli, Lucia Marrucci, andrea Taddei, prefazione di Riccardo Di Donato, Pisa, Edizioni ETS, 2004. 1 vol. $15,5 \times 22 \mathrm{~cm}, 287$ p. (Antropoi. Studi e materiali di Antropologia storica del mondo antico, 1). ISBN : 88-467-0945-4. 